\title{
Safety and Efficacy Assessment of Medicinal and Aromatic Plants Derived Products. A Qualitative Research
}

\author{
Roxana-Larisa CADAR, Cristina Bianca POCOL* \\ Department of Animal Production and Food Safety, University of Agricultural Sciences and Veterinary \\ Medicine of Cluj Napoca, Romania \\ * corresponding author: cristina.pocol@usamvcluj.ro
}

BulletinUASVM Horticulture 77(2) / 2020

Print ISSN 1843-5254, Electronic ISSN 1843-5394

DOI:10.15835/buasvmcn-hort: 2020.0032

\begin{abstract}
The complexity of medicinal and aromatic plants products makes difficult to asses their safety and efficacy. A qualitative research method, called hybrid forum has been used in order to better understand the risks and benefits of those products, from the perspective of three key components: the manufacturing process, from raw material to the finished product, safety and quality assurance, consumers' perception and biomedical context. The discussion forum took place in November 2019 in Cluj-Napoca and it was organized in two parts: the first addressed to researchers and actors in the field (14 stakeholders) and the second to the general public (23 participants). Critical points and limitations in the field of products obtained from medicinal and aromatic plants have been identified by both the specialists (poor cooperation between actors; lack of monitoring of product quality; increase selfmedication), and the general public (difficulties in making informed choices; reluctance to pharmacists' advice).
\end{abstract}

Keywords: actors, hybrid forum, medicinal and aromatic plants quality, security

\section{Introduction}

The history of using the medicinal and aromatic plants (MAPs) dates since back to the beginning of mankind, our ancestors being aware of their value and importance in improving the quality of life (Aliu and Aliu, 2017; Inoue et al., 2017). The first books on the use of medicinal and aromatic plants come from different parts of the world, such as The Middle East, Greece, China and India (Inoue et al., 2017), a large number of plants being used for more than 3000 years in traditional medical practices such as the Chinese and Ayurvedic medicine (Farnsworth and Soejarto, 1991). Despite their age, the medicinal plants are still at the basis of the health system in many developing countries. According to the
World Health Organization more than $80 \%$ of the population of developing countries use traditional medicine based on plants to treat health problems (Palhares et al., 2015).

Using as raw material the medicinal and aromatic plants (cultivated or from the spontaneous flora) a series of intermediary products can be obtained, products that could be useful in the pharmaceutical, food and cosmetic industry (Fig. 1) (Labbé, 2018), but also for their ornamental value (Ardelean et al., 2006).

In the last couple of years, there has been an increase in the use of natural products, many of which are associated with a healthy lifestyle and increased quality of life (Katsikis, 2019). Among the natural products are also products obtained 


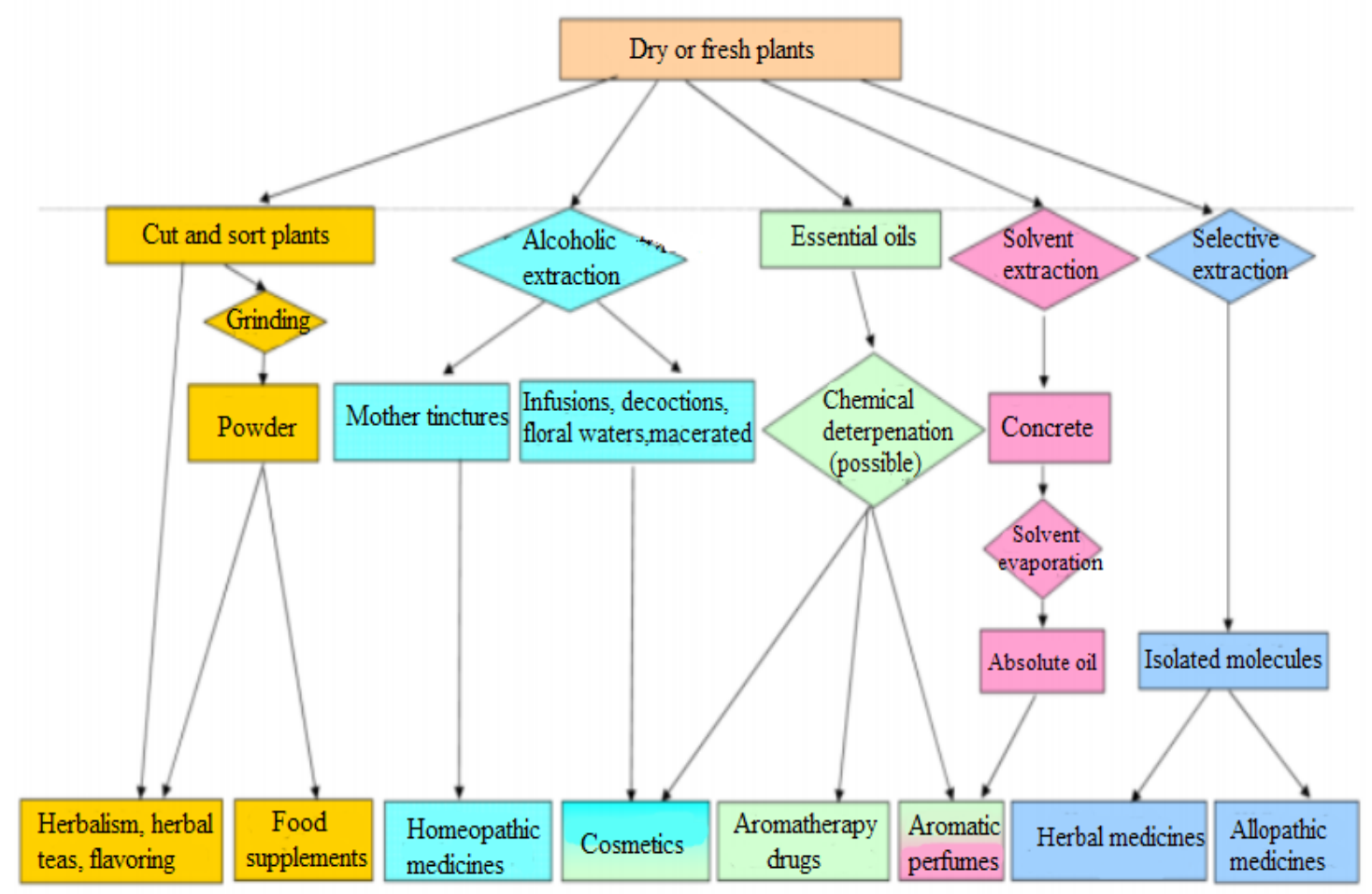

Figure 1. Products obtained from medicinal and aromatic plants Source: Labbé, 2018

from medicinal and aromatic plants: botanical supplements, vegetal extracts, natural cosmetics, essential oils, etc. (Labbé, 2018).

The general perception that herbal remedies are safe and free of side effects is not true (Ekor, 2014). The absence of evidence of a known health risk does not prove its absence (Nohynek, 2010). Some plants have been shown to be able to produce a wide range of adverse reactions, some of which are severe, potentially life-threatening (Ekor, 2014). There are many concerns related to the safety and the efficacy of using plants for health, such as exact dose, duration of the treatment, side effects, acute and chronic toxicity, as well as standardization of these products (Jamshidi-Kia et al., 2018).

In Romania, the medicinal and aromatic plants have been used since the Thracians. The first Romanian medical book was published in 1862 and it described 217 phytotherapeutic remedies, and the European research institute dedicated to medicinal and aromatic plants was founded in 1904 on Cluj by professor Béla Páter (Vasile, 2018). In the '80s local medicinal plants were exported to 20 countries, Romania being also on the 8th place in the volume of processed medicinal plants/year. However, small steps have been taken in the development of this sector in the last years. For example, when it comes to organic farming, in 2004 only 5 farms were interested in (Armanca, 2006).

To ensure the quality of the MAPs, a guidelines of good agricultural, collection and manufacturing practices was developed. Such practices aim to reduce the counterfeits and contaminants in plant materials placed on the market (Craker, 2007).

In Europe, only products obtained from MAPs that have complied with these guidelines are accepted for trade. The MAPs production must take into consideration the quality conditions of the industry and the national and European regulations, traceability being very important (Lubbe and Verpoorte, 2011).

As the market volume and the product variety increases, better product characterization and risk assessment are needed (Rietjens et al., 2008). The complexity and the variability of these products make it difficult to assess quality and safety (Shipkowski et al., 2018). 


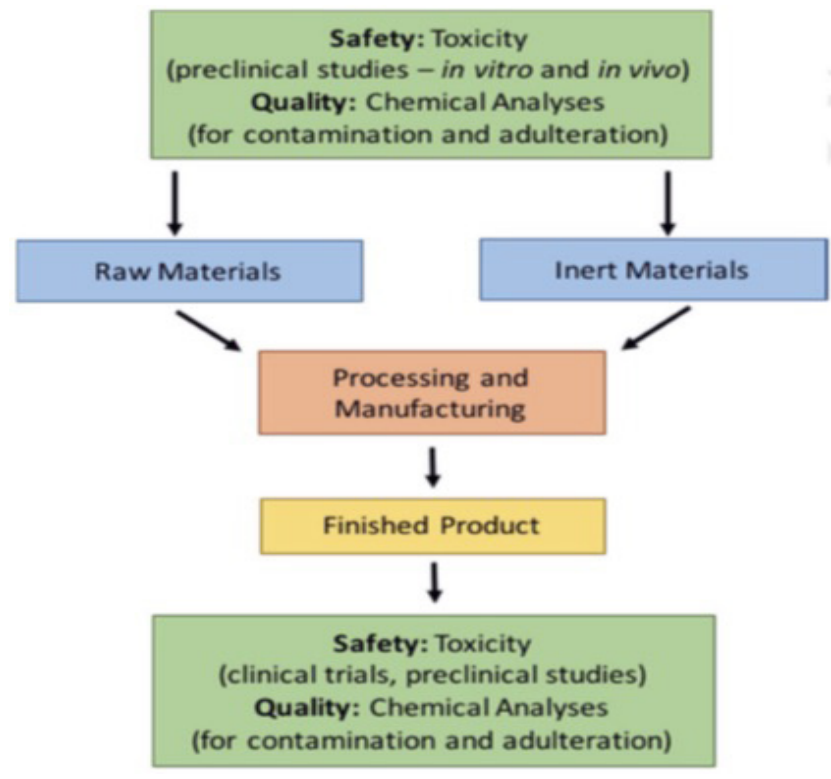

Figure 2. Reasons to ensure the safety and quality of botanical products Source: Shipkowski et al., 2018

The actors involved in the value chain of the products obtained from medicinal and aromatic plants (consumers, suppliers, manufacturers, regulation authorities, medical services providers, researchers) recognize the importance of ensuring the quality and the safety of these products at all stages of the technological process of obtaining, from harvesting the raw material to the storage of the final product (Fig. 2) (Shipkowski et al., 2018).

In the recent years, a reorganization of the value chain of medicinal and aromatic plants has taken place in Romania: new production and processing units have appeared, the demand for their authorization increased, new quality standards and analysis laboratories have emerged (Muntean et al., 2019). At the same time, a more positive attitude of consumers was observed related to the consumption of products obtained from MAPs, which led to an increase in their purchase intention (Oncioiu, 2017).

In this context, the purpose of this research was a better understanding of the risks and benefits of products obtained from medicinal and aromatic plants, as well as information regarding their quality and safety, from the perspective of three key components: the manufacturing process, from raw material to the finished product, ensuring safety and quality, consumers' perception and biomedical context.

\section{Materials and methods}

The research method used was a qualitative one, the hybrid forum. This method was recommended for the first time by Callon et al., (2009), in the book 'Acting in an uncertain world', in order to address controversial topics.

The hybrid forum represents a dynamic and democratic way (Callon et al., 2009) of stimulating dialogue between participants, addressing controversial topics, such as the safety and the efficacy of products obtained from medicinal and aromatic plants. This creates an atmosphere in which the actors involved and the general public get together to discuss and explore, to listen to each other's opinions regarding the chosen topic, finally reaching a better understanding of the field and building new ideas. All participants, from experts to the general public, may contribute with information and knowledge, and by revealing uncertainties and exploring constraints, it will facilitate the collective learning, the cooperation helping to enrich discussions and suggest innovative solutions (Callon et al., 2009).

Thus, by using the hybrid forum by the authors of this study, it was intended to create an efficient dialogue that may take into consideration critical points and limitations in the field of products obtained from medicinal and aromatic plants from the perspective of all the links involved in the value chain, from producer to consumer. The 
ultimate goal was not to reach a common solution or understanding, but to discover and build new ideas.

The hybrid forum took place at the University of Agricultural Sciences and Veterinary Medicine in Cluj-Napoca, at the Biodiversity Center, on the 4 th of November 2019. It lasted 5 hours, according to a previously established agenda, a moderator being responsible for conducting discussions.

The workshop had two parts, the first one addressed to researchers and important actors in the field, and the second one to the general public. The participants to the first part of the hybrid forum were local actors, selected in such way that at least one person, representing each interested parties, should be present: producers, up/down companies, retailers, teachers and consumers. As the workshop took place in the University Campus, at the second part the general public was represented mostly by students of master and doctoral degree of the University of Agricultural Sciences and Veterinary Medicine and Pharmacy, Cluj-Napoca, as well as pharmacists.

For the first part, 14 persons were present, selected so as to ensure the representativeness of each link from the value chain of the medicinal and aromatic plants: producers (cultivator/ harvesters), processors (both for obtaining vegetal supplements and natural cosmetics), distributors, traders, researchers and teachers. So, the participants were: farmers who grow medicinal and aromatic plants such as lavender, sage or mint, which they then process to obtain essential oils; persons responsible for sustainable harvesting of the medicinal plants from the spontaneous flora; natural cosmetics manufacturers; teachers and researchers with competences in phytotherapy, food supplements, pharmaceutical biotechnologies, food biotechnologies and cosmetology; doctors specialized in apy-phyto-aromatherapy and pharmacists.

The second part consisted of discussions between the persons present in the first part and the general public, represented by consumers and non-consumers of products obtained from medicinal and aromatic plants.

\section{Results and discussions}

The discussions in both the first and the second part were particularly stimulating and rich in content. The hybrid forum started with two lectures with different perspectives on the chosen topic, the first one aimed to present the advantages and the benefits of the products obtained from medicinal and aromatic plants, while the second one focused on the limitations and the constraints encountered in this field.

The topic being a vast one, during the discussions the information regarding the different products obtained from medicinal and aromatic plants came together, thus leading to discussions related both to food supplements and natural cosmetic products. Aspects related to the technological flow of obtaining products starting from the raw material were discussed, these processes being closely correlated with quality control and safety for the entire technologic process. An important link in this value chain is the beneficiary of these products, i.e. the consumer, as well as the representatives of the biomedical field, i.e. doctors, pharmacists, nutritionists.

Aspects resulted from the interventions of the specialists.

The specialists identified critical points in the technological process of obtained products derived from medicinal and aromatic plants, starting from the raw material to the finished product. A highlighted aspect was the fact that the process should start with analyzing the soil in which the plants will be cultivated, because it could be rich in heavy metals, pesticides or fertilizers.

Regarding the raw material, it seems that Romania is facing problems in supplying the seed material, being forced to turn to other countries (Hungary, Germany) "in Romania there are a lot of local population, but the content in active principles is lower".

An important aspect was highlighted by a professor specialized in field plant culture and the medicinal plant technology, namely, the poor collaboration between the manufacturers, processors, distributors and researchers and the fact that "there is no link from the cultivator to the consumer".

The advantages of such a collaboration "would favor the production of products beneficial to the population, very well certified", primarily due to the different skills of the people involved, the products can be subject to strict quality controls, performed by experts in the field, starting with the soil in which these plants are cultivated. In this way, products can be developed to high quality 
and safety standards, depending on the needs and requirements of consumers. According to experts, the involvement and the support of the state, to promote the cooperation between the local actors, would be of a great help.

Regarding the products obtained from medicinal and aromatic plants (supplements, natural cosmetics) there are European regulations regarding the quality conditions of such products, "the quality controls being extremely strict for those honest", counterfeiting such products could lead to severe consequences, such as closing the laboratory and stopping the production.

An issue identified as a result of these discussions was the lack of monitoring of product quality, and, because there are not enough persons to perform the controls in the field, there are manufacturers who evade, introducing on the market non-compliant products (counterfeit, with distorted composition, with fake or unproven statements on the labels.)

It's true: "we have legislation, (...) but we have no legislation on market control", living in "an extremely wild and uncontrolled world", in which an important role is played by the "producer and the producer's conscience."

The existence of rigorous testing of products regarding quality and safety was a key point addressed by specialists. "Unfortunately, in Romania there is not much support from the authorities when it comes to natural products, supplements", and to test, the costs are very high for the manufacturers, and many of them cannot afford it. These tests are needed to test the quality of products.

In addition, there are no laboratories or consulting companies to support the small producers. There are producers who need the help of specialists both for the preparation of the compliance file and for testing the products, so that when the product appears on the market to be sure it complies with the legal requirements, but in Romania "there are no laboratories to perform these analyzes, as well as there are no consultancy companies."

Regarding the information the consumers have about the benefits of the supplements, two questions were asked: "Do we need supplements?" and "Do they know their daily nutritional needs for a healthy, balanced diet, appropriate to their age and the physiological condition?"
The consumption of such products is recommended to be done on the advice of a specialist, taking into account age, sex, physiological condition of the patient, the degree of absorption of nutrients, as well as the risk of interaction with other drugs or supplements.

But in reality, "on what do consumers base their purchasing decisions?" the advice that patients receive from specialists may be contradictory, allopathic and alternative medicine addressing different treatment methods, thus creating confusion in the patient's mind, the responsibility of choosing being the consumer's.

Some patients don't trust the specialists, turning to "advice from the neighbor on the second floor". In addition, "many of the products are now found in supermarkets (...) the patient doesn't even meet with a specialist", aggressive promotion, expensive consultations, as well as limited time favoring self-medication, increasing thus the risk of interactions and side effects.

One solution proposed by the participants to the first part of the hybrid forum would be "to get involved more in educating the consumers, especially in their way of choosing."

Aspects resulted from the intervention of the public

In the second part, the main topics discussed were: proper education for the consumers, choosing the correct information sources, trusting the specialized personnel, as well as consumption practices for these products.

The vast majority of those present say that they have difficulty informing themselves correctly about these products, the abundance of advertisements presented in social media and on TV causing a lot of confusion and insecurity. One expressed wish was to educate consumers in this direction, because "an uneducated person is easily influenced" and improving access to concrete and valid information.

The lack of trust in pharmacists, due to the commercial aspect of their profession and the aggressivity of commercials in this field, was also strongly debated and accepted by many of those present, while others consider pharmacists specialists, accepting their recommendations.

In terms of consumption, some do not consume this type of products because they either do not need, or not trust their effectiveness, while others have used them but had allergic reactions, 
thus giving up their use. Of those who use them, the consumption of teas was the most frequently mentioned, some of them being involved even in harvesting the plant, this practice being learned from their grandparents. What many consumers participating in the hybrid forum did not know was that some teas, due to the active principles, may interact with other preparations, or cause side effects. An example would be St. John's wort tea, which may reduce the effectiveness of certain drugs due to its enzyme-inducing effect. Also, the consumption of plants harvested directly from nature can lead to the use of species unsuitable for human consumption, or their use in inappropriate doses. There were also people who us or used supplements in the form of tablets, capsules or extracts and they were very happy with the obtained results. As stated in the discussions, such treatments may require a longer time until the results appear, compared to allopathic therapy, therefore, the patient's patience and consistency are important for the effectiveness of the treatment.

The participants were involved and engaged in discussions, listening and learning from each other, the aim being to increase the level of knowledge in the field, to identify the limiting areas, as well as factors that hinder the development and the promotion of these products whose quality and safety is certified. The discussions held in this hybrid forum do not end with simple solutions, but on the contrary, leave room for analysis and research of this complex subject.

The inadequate product quality remains a problem for the use of medicinal and aromatic plants. This is frequently organoleptic assessed, by color, aroma, taste and the effect of the vegetal material, and the levels of various chemical components can be analyzed in testing laboratories (Craker, 2007).

The ways in which the vegetal raw material can be contaminated was a topic addressed by the specialists in the first part of the hybrid forum. Thus, the contaminations can occur either due to the soil conditions (metals) and the applied treatments (pesticides), or during tharvesting (coharvesting of other plant species or other materials - soil, insects) or storage (bacteria or fungi) (Wang et al., 2015). In addition, contaminants may occur in finished products during the manufacturing and preparation processes and they can include undeclared synthetic substances (pharmaceutical products and related compounds) and metals. Intentional adulteration of botanical products with chemical pharmaceutical substances is a significant concern worldwide (Shipkowski et al., 2018). This issue was also discused in the forum, the lack of monitoring of product quality being the reason why non-compliant products appear on the market.

On the other hand, organic fertilization can positively influence the soil properties and therefore of medicinal plants, such as root growth as shown by Angelopoulou et al. (2014) for oregano and milk thistle. Irrigation can also positively affect the growth and development of the root system with a beneficial impact on overall plant growth and productivity (Bilalis et al., 2014). Plant breeding in order to develop or improve certain characteristics is another topic studied by many researchers (Ardelean et al., 2006).

According to Dietary Supplement Health and Education Act, there is no requirements for the manufacturers to assess the safety of the new products before releasing them on the market in case they contain ingredients with an appropriate market history (Roberts et al., 2019). The large number of products on the market and the variability between products, however, prevent the testing of all available botanical supplements (Roberts et al., 2019), issue pointed out by the specialists present at the forum.

The regulator authorities are aware of these issues and they are considering appropriate actions to protect the public, such as: setting tolerable daily intakes, enforcing limits on the presence of certain compounds, as well as informing the public of possible side effects (Rietjens et al., 2008). From the study conducted by Marinac et al. (2007) resulted that the most respondents erroneously considered that Food and Drug Administration tests and regulates botanical products.

As stated by the participants in the Hybrid Forum, among the possible side effects of botanical food supplements is the interaction with other drugs (Sprouse and Van Breemen, 2016). Korobkova (2015) reviewed the effect of natural polyphenols, that can be found in many botanical supplements, on the activity of cytochrome P450 enzymes. It was found that many flavonoids could modulate the activities of CYP3A4, CYP2C9 and CYP1A2 and, therefore, interfere with drug metabolism (Korobkova, 2015). 
In the case of natural cosmetics, the manufacturer has an important role in ensuring the safety of products placed on the market (Nohynek, 2010), which was also highlighted in this research. Thus, a safety assessment of the finished products is required, taking into consideration the toxicologic profile of the ingredients, their chemical structure and their potential of producing local or potentially systemic exposure, some products may contain different amounts of contact allergens (Nohynek, 2010).

As our research specialists said, among the issues the Romanian market is facing are also: poor collaboration between authorities, lack of correlation between agricultural activity and the industrial activity, lack of laboratories and efficient testing methods, lack of local certified seed sources, lack of certification stations, as well as lack of support from government institutions (Rural Romania, 2015; Oncioiu, 2017)

The specialists present at the forum have also discussed the poor collaboration between producers, processors, distributorsandresearchers involved in the value chain of the medicinal and aromatic plants, as well as about the advantages of such collaboration. According to Aliu and Aliu (2017), the collaboration between different actors in the sector of MAPs, the government institutions and researchers is essential to consolidate and ensure the sustainability of the MAPs industry. The involvement of processors in training the persons involved in harvesting the medicinal plants, as well as their collaboration with researchers in the field could lead to an increase quality of the finished products (Aliu and Aliu, 2017).

Other researchers that have studied the consumers' attitudes towards the products obtained from medicinal and aromatic plants show the use of MAPs, especially for therapeutic, preventive and welfare purposes (Korkmaz et al., 2011, Brousse and Gallé, 2017), in the top of preferences being herbal teas, balms/ointments/creams and essential oils (Brousse and Gallé, 2017), the tea consumption was also the most frequently mentioned case of this research. The hybrid forum was also attended by people who do not consume this type of products for various reasons: they do not need it, they do not trust their efficacity or they gave them up because they have had side effects.

During the discussions in the workshop, it was recommended the use of products obtained from medicinal and aromatic plants upon the advice of a specialist. However, other researches showed that in terms of knowledge of medicinal plants, consumers give little credit to family doctors and pharmacists (Brousse and Gallé, 2017). The lack of trust in the pharmacists was mentioned by some participants in the discussions. Their use upon doctor's recommendation has a low frequency (Korkmaz et al., 2011), while advice and recommendation received from loved ones largely influence consumption habits (Korkmaz et al., 2011). The lack of trust in specialists, as well as the limited time to consult a specialist are factors favoring the self-medication (Ekor, 2014), aspects confirmed by some participants in the discussions.

Television and internet access are major sources of information for the young people about the natural products (Greger, 2001), which is why during the forum we have addressed the importance of choosing the correct information sources. After analysing the way in which the risks and benefits of botanical supplements are presented in newspaper/magazines in Great Britain, Romania and Italy, Peacock et al., (2019) considered that it is necessary for consumers to have access to reliable sources of information, and the provision of such information should not be the responsibility of media.

Regarding consumer's knowledge about possible side effects of products obtained from medicinal and aromatic plants, the participants' opinions were divided. Other researches have shown that consumers are aware of the possibly toxicity of plant products, the main risks associated with plants being the wrong dosage or administration in situations when they should be counter-indicated (pregnancy for example) (Brousse and Gallé, 2017). Contrary results were observed in the study by Korkmaz et al. (2011), where most of respondents were unaware of the side effects of the products they consume.

As with the present research, a study that looked at consumers' views regarding the risks and the benefits of botanical products concluded that people need clear information about the risks and benefits of herbal products to use these products safely and efficiently. (Lynch and Berry, 2007). 


\section{Conclusion}

The medicinal and aromatic plants industry is a growing industry, which faces many challenges, like the complexity and variability of these products. The research in the field of botanical products requires a precise characterization of these products, the aspects of safety and efficacy being important stages throughout the technological process, being also important objectives in the field of public health (Shipkowski et al., 2018).

The botanical industry is a field gaining ground in Romania, but it is very little controlled in all its staged. Following discussions within the hybrid forum were identified critical points from the technological process of obtaining the products, to quality control and safety and to the beneficiary and the biomedical side.

Thus, the interventions of the specialists revealed that there are major deficiencies in the implementation and compliance with the legislation in the field, which, although it exists, is not doubled by the activity of certain institutions to monitor the quality of the product and their marketing process.

The specialists also considered that there is a low degree of information of the public about the products obtained from medicinal and aromatic plants, their effects, as well how they should be consumed.

From the interventions of the public, a relatively low interest in the consumption of these products emerged, in the absence of medical conditions. The interest seems to be even lower among young people, who do not know how to identify quality products, or require too much time and involvement, as adequate information is not available. Consumption of these products is done rather "by ear", without consulting specialists in the field, rather under the influence of aggressive mass-media marketing. Although they are willing to find safe and efficient products, there is a reluctance to pharmacists' advice.

Limitations. Hybrid forums were proposed by Callon et al. (2009) as spaces to address specific controversies, contributing to the enrichment of democracy and knowledge in the field, but because of the term "controversy" should not be confused with dispute.The existing literature on hybrid forums is limited, so given the type of methodology used, it is difficult to generalize the results, but further research will be done on the safety and efficacy of medicinal and aromatic plants products, focusing on the knowledge and behavior of the consumer in the field.

Acknowledgments. The study was conducted under a project entitled "Réseau régional francophone sur la santé, la nutrition et la sécurité alimentaire-SAIN", 2017-2019, financed by "L'Agence Universitaire de la Francophonie en Europe Centrale et Orientale".

\section{References}

1. Aliu A, Aliu D (2017). Collaborations and sustainability in medicinal and aromatic plants industry: examining the business communication amongst stakeholders in maps industry. In ICPESS (International Congress on Politic, Economic and Social Studies) No. 2.

2. Angelopoulou F, Kakabouki I, Papastylianou P, Papatheohari Y, Konstantas A, Karkanis A, Travlos I, Bilalis D. (2014). Effect of Organic Fertilization on Growth and Development of the Root System of two Medicinal Plants, oregano (Origanum vulgare L.) and milk thistle (Silybum marianum L. Gaertn.). Bulletin UASVM Cuj-Napoca. Horticulture, 71(2): 201-206.

3. Ardelean M, Costea AM, Cordea M (2006). Breeding foxglove (Digitalis sp.) for ornamental and/or medical purposes. Bulletin of UASVM Cluj-Napoca. Horticulture, 63(1-2): 22-31.

4. Armanca L (2006). Trend in the Utilization of Medicinal and Aromatic Plants. Bulletin of UASVM Cluj-Napoca. Horticulture, 63(1-2): 130-132.

5. Brousse CB, Gallé J (2017). Analyse des résultats de l'enquête consommateurs mise en ligne par la Fédération des Paysan.e.s - Herboristes. Rapport finale.

6. Bilalis D, Kakabouki I, Angelopoulou F, Papastylianou P, Karkanis A, Konstantas A, Travlos I (2014). Effect of Irrigation on Growth and Development of the Root System of Two Medicinal Plants, Hyssopus officinalis and Passiflora incarnata. Bulletin of UASVM Cluj-Napoca. Horticulture, 71(2), 212-217.

7. Callon M, Lascoumes P, Barthe Y (2009). Acting in an Uncertain World: An Essay on Technical Democracy, MIT, Cambridge, MA and London.

8. Craker LE (2007). Medicinal and Aromatic Plants-Future Opportunities. In: Issues in new crops and new uses, p. 248-57.

9. Ekor M (2014 Jan 10). The growing use of herbal medicines: Issues relating to adverse reactions and challenges in monitoring safety. Front Neurol., 4 JAN:177.

10. Farnsworth N, Soejarto D (1991). Global importance of medicinal plants. In: Conservation of Medicinal Plants, pp. 25-51.

11. Greger JL (2001). Dietary supplement use: consumer characteristics and interests. The Journal of Nutrition, 131(4): 1339S-1343S

12. Inoue M, Hayashi S, Craker LE (2017). Culture, History and Applications of Medicinal and Aromatic Plants in 
Japan. In: Aromatic and Medicinal Plants - Back to Nature. InTech.

13. Jamshidi-Kia F, Lorigooini Z, Amini-Khoei H (2018). Medicinal plants: Past history and future perspective. Journal of herbmed pharmacology, 7(1).

14. Katsikis IN (2019). Market demand, eco-products and entrepreneurship in the "natural cosmetics sector" in Greece. In: Entrepreneurship, Innovation and Sustainability. Routledge, pp. 238-51.

15. Korkmaz M, Fakir H, Guller B (2011). Consumer preferences for medicinal and aromatic plant products: Surveys of urban consumers and sellers in western Mediterranean region of Turkey. Journal of Medicinal Plants Research, 5(10): 2054-2063.

16. Korobkova EA (2015 Jul 20). Effect of Natural Polyphenols on CYP Metabolism: Implications for Diseases. Chem Res Toxicol, 28(7): 1359-90.

17. Lynch N, Berry D (2007) Differences in perceived risks and benefits of herbal, over-the-counter conventional, and prescribed conventional medicines, and the implications of this for safe and effective use of herbal products, Complementary therapies in medicine, 15(2): 84-91.

18. Lubbe A, Verpoorte R (2011). Cultivation of medicinal and aromatic plants for specialty industrial materials. Industrial crops and products, 34(1): 785-801.

19. Marinac C, Buchinger L, Godfrey J, Wooten C, Sun C, Willsie SK (2007). Herbal products and dietary supplements: a survey of use, attitudes and knowledge among older adults, The Journal of the American Osteopathic Association, 107(1): 13-23.

20. Muntean LS, Muntean L, Muntean S, Florian S (2019) The Status Of Medicinal And Aromatic Plant Culture And Exploitation In Romania, Hop and Medicinal Plants, 27(12): 7-15.

21. Nohynek GJ, Antignac E, Re T, Toutain H (2010). Safety assessment of personal care products/cosmetics and their ingredients. Toxicology and applied pharmacology, 243(2): 239-259.

22. Oncioiu I (2017). Supporting Herbal Agriculture Market in Romania- Desideratum or Reality. Acta Universitatis Danubius. EEconomica, 13(6).
23. Palhares RM, Drummond MG, Dos Santos Alves Figueiredo Brasil B, Cosenza GP, Das Graças Lins Brandão M, Oliveira G (2015 May 15). Medicinal plants recommended by the world health organization: DNA barcode identification associated with chemical analyses guarantees their quality. PLoS One, 10(5).

24. Peacock M, Badea M, Bruno F, Timotijevic L, Laccisaglia M, Hodgkins C, Egan B (2019). Herbal supplements in the print media: communicating benefits and risks. BMC complementary and alternative medicine, 19(1): 196.

25. Rietjens IM, Slob W, Galli C, Silano V (2008). Risk assessment of botanicals and botanical preparations intended for use in food and food supplements: Emerging issues. Toxicology letters, 180(2): 131-136.

26. Roberts GK, Gardner D, Foster PM, Howard PC, Lui E, Walker L, Rider C (2019). Finding the bad actor: Challenges in identifying toxic constituents in botanical dietary supplements. Food and Chemical Toxicology, 124: 431-438.

27. Rural Romania (2015). National Rural Development Network, 2(15).

28. Shipkowski KA, Betz JM, Birnbaum LS, Bucher JR, Coates PM, Hopp DC, Rider CV (2018). Naturally complex: Perspectives and challenges associated with Botanical Dietary Supplement Safety assessment. Food and Chemical Toxicology, 118: 963-971.

29. Sprouse AA, van Breemen RB (2016). Pharmacokinetic interactions between drugs and botanical dietary supplements. Drug Metabolism and Disposition, 44(2): 162-171.

30. Vasile D, Enescu CM, Dincă L (2018). Which Are The Main Medicinal Plants That Could Be Harvested From Eastern Romania? Scientific papers series Management, Economic Engineering in Agriculture and Rural Development, 18: 523-528.

31. Wang Z, Huang L (2015). Panax quinquefolius: An overview of the contaminants. Phytochemistry Letters, 11: 89-94. 